\title{
Clinical potential of lurasidone in the management of schizophrenia
}

This article was published in the following Dove Press journal:

Therapeutics and Clinical Risk Management

24 June 2011

Number of times this article has been viewed

\section{Ludovic Samalin \\ Marion Garnier \\ Pierre-Michel Llorca \\ Centre Hospitalier Universitaire, Clermont-Ferrand, France}

Correspondence: $\mathrm{L}$ Samalin

Centre Médico-Psychologique

B, Centre Hospitalier Universitaire,

BP 69, 63003 Clermont-Ferrand

Cedex I, France

Tel +33047375 2125

Fax +33047375 2126

Email Isamalin@chu-clermontferrand.fr
Abstract: Lurasidone is a new second-generation antipsychotic approved in October 2010 by the Food and Drug Administration for the treatment of schizophrenia. Like other second-generation antipsychotics, lurasidone is a powerful antagonist of $\mathrm{D}_{2}$ dopamine and $5 \mathrm{HT}_{2 \mathrm{~A}}$ serotonin receptors, but differs from the other second-generation antipsychotics in its action profile for certain receptors. Lurasidone is the second-generation antipsychotic with the greatest affinity for $5 \mathrm{HT}_{7}$ receptors and has a high affinity for $5 \mathrm{HT}_{1 \mathrm{~A}}$ serotonin receptors, compatible with favorable effects on cognitive function and an antidepressant action. By contrast, lurasidone has a low affinity for $\alpha_{1}$ and $\alpha_{2 \mathrm{C}}$-adrenergic and 5HT $2 \mathrm{C}$ serotonin receptors, and no affinity for histaminergic $\mathrm{H}_{1}$ or muscarinic $\mathrm{M}_{1}$ receptors, suggesting a better tolerability profile than the other second-generation antipsychotics. Lurasidone has demonstrated its efficacy in several short-term trials in acute schizophrenia, promptly and significantly reducing total Positive and Negative Syndrome Scale and Brief Psychiatric Rating Scale scores compared with placebo. Several long-term studies are in progress to assess its efficacy in the maintenance treatment of schizophrenic patients. The efficacy of lurasidone with regard to cognitive functions and depressive symptoms seems good, but requires further work. Lurasidone differs from the other second-generation antipsychotics by having a good tolerability profile, in particular for cardiometabolic tolerability. However, it seems to have a significant although moderate link with the occurrence of akathisia, extrapyramidal symptoms, and hyperprolactinemia at the start of treatment. This tolerance profile greatly broadens the scope of second-generation antipsychotics and so supports the view of some authors that the term "second-generation antipsychotic" is now outdated. Other therapeutic perspectives of lurasidone are assessed here, in particular bipolar depression.

Keywords: lurasidone, second-generation antipsychotic, schizophrenia, efficacy, safety

\section{Management issues in schizophrenia}

Schizophrenia is a serious chronic mental illness that appears in late adolescence or early adulthood, and affects about $1 \%$ of the world's population. ${ }^{1}$ It is a heterogeneous condition characterized by positive and negative symptoms, and is often associated with cognitive disorders and symptoms of depression.

Pharmacological treatment is based essentially on antipsychotics. These drugs are central to care because they offer the only efficacious treatment for most of the symptoms. They allow both treatment of acute phases and the prevention of relapses.

Clozapine, introduced into the US in 1988, differed from classical neuroleptics not only in its greater efficacy but also, more importantly, by having markedly reduced neurological effects. ${ }^{2}$ With this compound as leader, the atypical antipsychotics appeared at the end of the 1990s. However, atypicalness is a catch-all classification that is extremely 
difficult to exploit operationally. The atypical antipsychotics form a heterogeneous group that have a pharmacodynamic action on neurotransmission that is different from that of the neuroleptics, with involvement of other neurotransmission systems, few or no induced extrapyramidal effects, and stronger activity on negative schizophrenic symptoms. ${ }^{3}$ This very loose definition prompted a new terminology, ie, the terms "first-generation" and "second-generation" antipsychotics, which have been in use since 2004 .

The second-generation antipsychotics are recommended in various guidelines as first-line treatment in view of their better neurological tolerability, and their greater efficacy on negative, cognitive, and depressive symptoms. ${ }^{4-7}$ They include the chemical entities amisulpride, aripiprazole, asenapine, clozapine, iloperidone, olanzapine, paliperidone, quetiapine, risperidone, sertindole, ziprasidone, and zotepine.

The superiority of second-generation antipsychotics over first-generation antipsychotics has been the subject of much debate, based on several meta-analyses published since 2000. Some authors are not convinced of the superiority of second-generation antipsychotics and point to the poor methodological quality of the comparative trials in terms of evaluation criteria, dropouts, and choice and dose of comparator. ${ }^{8,9}$ A more recent meta-analysis singled out four second-generation antipsychotics that displayed greater overall efficacy compared with first-generation antipsychotics, namely clozapine, amisulpride, risperidone, and olanzapine. The other second-generation antipsychotics were no more efficacious than the older first-generation antipsychotics, even for negative symptoms. ${ }^{10}$

This difference in efficacy among the second-generation antipsychotics was confirmed in a meta-analysis of headto-head comparisons of second-generation antipsychotics. Olanzapine was found to be more efficacious than aripiprazole, quetiapine, risperidone, and ziprasidone, and of similar efficacy to amisulpride and clozapine. ${ }^{11}$ This difference among second-generation antipsychotics showed up mainly in the Positive and Negative Syndrome scale (PANSS) positive symptom subscores, and was small in the PANSS negative symptom subscores. CATIE (Clinical Antipsychotic Trials in Intervention Effectiveness) and CUtLASS (Cost Utility of the Latest Antipsychotic Drugs in Schizophrenia Study) gave similar results, except that clozapine stood apart from both first-generation antipsychotics and other second-generation antipsychotics. ${ }^{12,13}$

Concerning tolerability, whereas second-generation antipsychotics induced much weaker neurological side effects, they induced metabolic (weight gain, hyperglycemia, and dyslipidemia) and cardiac side effects (QT prolongation) requiring regular monitoring. Differences were also found among the second-generation antipsychotics. Although inducing fewer extrapyramidal effects compared with firstgeneration antipsychotics, risperidone was associated with greater use of antiparkinsonian medication than clozapine, olanzapine, quetiapine, and ziprasidone. ${ }^{14}$ Also, concerning metabolic side effects, olanzapine and clozapine produced more weight gain than all the other second-generation antipsychotics, and olanzapine produced a higher rise in cholesterol than aripiprazole, risperidone, and ziprasidone. ${ }^{15}$

Overall, these recent data confirm that second-generation antipsychotics are not a homogeneous group, that each second-generation antipsychotic possesses distinct pharmacodynamic properties, and that consequently any new member may be of therapeutic interest. Lurasidone is a second-generation antipsychotic that was approved by the Food and Drug Administration (FDA) in October 2010 for the treatment of schizophrenia. Here we present the data available for this new agent concerning its pharmacological properties, efficacy, and tolerability in schizophrenic patients, and show the position of lurisadone with respect to the other second-generation antipsychotics.

\section{Data sources}

A literature search using the keywords "lurasidone" and "schizophrenia" was undertaken using the databases PubMed and EMBASE to find all the relevant studies published in English. Additional references were identified from http:// www.fda.gov and http://clinicaltrials.gov. ${ }^{16}$ Data were also collected from product user information. ${ }^{17}$ Searches were last updated on March 12, 2011.

\section{Pharmacology and drug interactions Pharmacological profile}

Lurasidone is a benzoisothiazol derivative (SM-13496; (3aR,4S,7R,7aS)-2-[(1R,2R)-2-[4-(1,2-benzisothiazol-3-yl) piperazin-1-ylmethyl] cyclohexylmethyl] hexahydro-4, 7-methano-2H-isoindole-1,3-dione hydrochloride).

Like the other second-generation antipsychotics, lurasidone is a powerful antagonist of the dopamine $\mathrm{D}_{2}$ and serotonin $5 \mathrm{HT}_{2 \mathrm{~A}}$ receptors, with a strong affinity for the $5 \mathrm{HT}_{2 \mathrm{~A}}$ receptor $\left(K_{\mathrm{i}}=0.470-0.357 \mathrm{nM}\right)$ and very high selectivity for the $\mathrm{D}_{2}$ receptor $\left(K_{\mathrm{i}}=0.329-0.994 \mathrm{nM}\right) 264,16$, and 30 times greater, respectively, compared with $\mathrm{D}_{1}, \mathrm{D}_{3}$, and $\mathrm{D}_{4}$ receptors. ${ }^{16}$ In a preliminary trial using positron emission 
tomodensitometry in 21 healthy subjects, it was shown that the degree of occupation of $\mathrm{D}_{2}$ receptors at lurasidone dosages of $10,20,40,60$, and $80 \mathrm{mg}$ ranged from $41.3 \%$ to $43.3 \%$, $51 \%$ to $54.8 \%, 63.1 \%$ to $67.5 \%, 77.4 \%$ to $84.3 \%$, and $72.9 \%$ to $78.9 \%$, respectively. An antipsychotic response, for which an occupation of $60 \%-80 \%$ of the receptors is required, could thus be expected from $40 \mathrm{mg} /$ day. ${ }^{18}$

Lurasidone differs from other second-generation antipsychotics in its action profile for certain receptors. In vitro studies have shown that lurasidone is the second-generation antipsychotic that shows the greatest affinity for $5 \mathrm{HT}_{7}$ receptors $\left(K_{\mathrm{i}}=0.495-2.10 \mathrm{nM}\right)$ and a high affinity for $5 \mathrm{HT}_{1 \mathrm{~A}}$ receptors. ${ }^{16,19} 5 \mathrm{HT}_{7}$ receptors are abundant in the thalamic and hypothalamic regions involved in the regulation of sleep, and in the cortical areas and the regions of the hippocampus and raphe nuclei involved in memory and mood regulation. ${ }^{20,21}$ Therefore, via these two receptors, lurasidone should have favorable effects on memory and cognitive functions, together with an antidepressive and anxiolytic action. ${ }^{22}$

In contrast with its high affinity for the $5 \mathrm{HT}_{7}$ and $5 \mathrm{HT}_{1 \mathrm{~A}}$ receptors, lurasidone has a moderate affinity for $\alpha_{2 \mathrm{C}}$ adrenergic receptors, a very weak affinity for $\alpha_{1}$-adrenergic and serotonin $5 \mathrm{HT}_{2 \mathrm{C}}$ receptors, and no affinity for histaminergic $\mathrm{H}_{1}$ or muscarinic $\mathrm{M}_{1}$ receptors. ${ }^{16,19}$ Through its action on these different receptors, lurasidone should have a better tolerability profile than the other antipsychotics, in particular less risk of orthostatic hypertension ( $\alpha_{2 \mathrm{C}}$ and $\alpha_{1}$ receptors), less weight gain $\left(\mathrm{H}_{1}\right.$ and $5 \mathrm{HT}_{2 \mathrm{C}}$ receptors), less sedative effect $\left(\mathrm{H}_{1}\right.$ and $\mathrm{M}_{1}$ receptors $)$ and fewer anticholinergic effects $\left(\mathrm{M}_{1}\right.$ receptors). ${ }^{18}$

In vivo studies in animal models have shown that, compared with other antipsychotic drugs, lurasidone carries a low risk for extrapyramidal symptoms or central nervous system depressive effects (motor coordination, muscle relaxation, anesthesia potentiation, bradykinesia, and catalepsy). ${ }^{19}$

\section{Pharmacokinetics}

Lurasidone is rapidly absorbed after oral administration, reaching peak concentrations $\left(\mathrm{T}_{\max }\right)$ in 1-3 hours. ${ }^{17}$ Absorption is dose-dependent. For dosages in the range of 20-160 mg/day, the area under the curve (AUC) and peak concentration $\left(\mathrm{C}_{\max }\right)$ increase linearly with the absorbed dose. ${ }^{17}$ Absorption is apparently favored by eating, as could be observed for ziprazidone. About 9\%-19\% of the dose administered is absorbed with no associated food intake, whereas AUC and $\mathrm{C}_{\max }$ are increased three-fold when at least 350 calories of food is ingested concomitantly. Eating has no effect on $\mathrm{T}_{\max } \cdot{ }^{17}$
Steady-state is reached within seven days. For a lurasidone dose of $40 \mathrm{mg}$, a distribution volume estimated at $6173 \mathrm{~L}$ and a clearance of $3902 \mathrm{~mL} / \mathrm{min}$ have been reported. ${ }^{17}$ The mean elimination half-life in trials including healthy subjects given a single dose of $100 \mathrm{mg} /$ day was $12.2-18.3$ hours, reaching 36 hours after nine days. The mean half-life in schizophrenic patients with single doses of 120-160 mg/day was 28.8-37.4 hours. $^{18}$

The lurasidone molecule binds very strongly to plasma proteins $(99.8 \%)$, in particular to albumin and $\alpha 1$-glycoprotein. ${ }^{23}$ Lurasidone is metabolized in the liver, principally by the cytochrome P450 (CYP) isoenzyme, CYP3A4, into three active and two inactive metabolites. The main active metabolite, ID-14283, an exohydroxy metabolite, is rapidly detected in the serum, with a $\mathrm{C}_{\text {max }}$ value equal to $26 \%$ of the starting material. It has a comparable pharmacological profile, but a shorter life (7.48-10 hours) than lurasidone. The other two metabolites, ID-14326 and ID-11614, are present at extremely low levels of 3\% and $1 \%$, respectively. ${ }^{18}$

Lurasidone crosses the placental barrier. ${ }^{16}$ Approximately $89 \%$ is excreted in urine and stools. After administration of $\left[{ }^{14} \mathrm{C}\right]$-lurasidone, $80 \%$ of the radioactivity was found in stools and $9 \%$ in urine. ${ }^{17}$

$\mathrm{C}_{\max }$ and AUC values increased in patients with mild, moderate, or severe renal and hepatic insufficiency, suggesting that dosages should be adapted in these subjects. ${ }^{17}$ There seems to be no impact of race or age on the pharmacokinetics. Blood assays carried out in psychotic patients aged 65-85 years taking lurasidone $20 \mathrm{mg}$ /day showed concentrations identical to those in young subjects. ${ }^{17}$

\section{Drug interactions}

Because of hepatic metabolism of lurasidone by CYP3A4, there is a risk of drug interaction if lurasidone is taken concomitantly with inhibitors or inducers of this enzyme (diltiazem, ketoconazole, or erythromycin). ${ }^{17,18,23}$ Because lurasidone is not metabolized by CYP2D6, coprescription with inhibitors of CYP2D6, such as fluoxetine, paroxetine, and quinidine, needs no dosage adaptation. Lurasidone is not a substrate for $\mathrm{P}$ glycoprotein. No drug interactions have been observed when lurasidone is coprescribed with P glycoprotein substrates such as digoxin, or CYP3A4 substrates such as midazolam, oral contraceptives, or lithium. ${ }^{17,18}$ The high plasma protein-binding power of lurasidone, especially towards albumin and $\alpha 1$-glycoprotein, should be taken into account to avert certain drug interactions, in particular in undernourished subjects or the elderly. 


\section{Efficacy in schizophrenia}

The efficacy of lurasidone in acute schizophrenia was assessed in eight trials (Table 1). Six short-term (six-week) randomized, double-blind, placebo-controlled trials (of which three used an active comparator, ie, haloperidol, olanzapine, or quetiapine) in acute schizophrenia, a shortterm (three-week) randomized, double-blind controlled trial (versus ziprasidone) in stable outpatients with schizophrenia or schizoaffective disorder, and a short-term (eight-week) randomized, double-blind dose-response study in inpatients and outpatients with schizophrenia.

The primary efficacy endpoint in all the trials was the mean change in PANSS or Brief Psychiatric Rating Scale (BPRS) total score from baseline to endpoint. Secondary endpoints included changes in Clinical Global Impression of Severity (CGI-S) and PANSS subscale scores. One study evaluated cognitive efficacy with a subset of the MATRICS Consensus Cognitive Battery (MCCB) and Schizophrenia Cognition Rating Scale. ${ }^{24}$

Placebo-controlled trials (except for one failed trial) demonstrated antipsychotic efficacy in all primary and secondary efficacy measures in favor of lurasidone $80 \mathrm{mg} /$ day. With the exception of two trials (one failed trial and D1050229), efficacy was found at lurasidone doses of 40 , 120 , and $160 \mathrm{mg} /$ day.

A pooled analysis based on five PANSS factor scores (positive, negative, disorganized thought, hostility, and depression/anxiety) was performed from four shortterm, double-blind, placebo-controlled trials (D1050006, D1050196, D1050229, and D1050231). ${ }^{25}$ Despite the inclusion of a trial that did not find lurasidone to be efficacious at 40 or $120 \mathrm{mg} /$ day, pooled data found lurasidone to be significantly better than placebo in improving all five PANSS factor scores. At week 6, changed scores and effect sizes were significant compared with placebo among patients treated with lurasidone at $40 \mathrm{mg}, 80 \mathrm{mg}$, and $120 \mathrm{mg}$ (Table 2).

Significant improvement in the different scores (BPRS, PANSS, and CGI-S) was observed by days 3-7 for the $80-160 \mathrm{mg} /$ day doses. ${ }^{16,26,27}$ In a study of stable patients, lurasidone $120 \mathrm{mg} /$ day had an efficacy comparable with that of ziprasidone $160 \mathrm{mg} /$ day, but with an earlier onset of improvement in PANSS total score (by day 7). ${ }^{28}$ These trials suggest an early onset of treatment effect for lurasidone.

Trial results did not suggest any additional benefit of lurasidone $120 \mathrm{mg} /$ day over $40 \mathrm{mg} /$ day or $80 \mathrm{mg} /$ day (based on observed mean differences from placebo). ${ }^{16}$ Pooled analysis found the treatment effect of lurasidone to be consistent across the dosage range, with no clear superiority of the highest lurasidone dose. ${ }^{25}$ No dose-response relationship for lurasidone was found.

A dose-response study of lurasidone 20,40 , and $80 \mathrm{mg} /$ day found that the $40 \mathrm{mg}$ /day and $80 \mathrm{mg}$ /day doses were associated with significant improvements from baseline on the PANSS and BPRS, and were significantly better than $20 \mathrm{mg} /$ day. ${ }^{29}$ The starting dose of lurasidone recommended by the FDA is $40 \mathrm{mg}$ once daily, and the maximum dose is $80 \mathrm{mg}$ once daily.

The receptor binding profile of lurasidone, with high affinity for $5 \mathrm{HT}_{7}, 5 \mathrm{HT}_{1 \mathrm{~A}}$, and $\alpha_{2 \mathrm{C}}$ receptors, and negligible affinity for muscarinic $\mathrm{M}_{1}$ and histaminic $\mathrm{H}_{1}$ receptors, was associated with a potential effect on cognitive function in schizophrenia. ${ }^{19}$ Data from placebo-controlled studies demonstrated a significant improvement in the PANSS cognitive symptoms subscale (including conceptual disorganization, poor attention, and difficulty in abstract thinking) ${ }^{27}$ However, this subscale has not demonstrated a close correlation with performance-based cognitive tests. ${ }^{30}$

The cognitive effect of lurasidone was evaluated in comparison with ziprasidone in a short-term, randomized, double-blind trial. The outcome measures used were a performance-based cognitive assessment battery with most of the tests coming from the MCCB and an interviewer-rated measure of cognitive functioning, ie, the Schizophrenia Cognition Rating Scale. There were no between-group treatment differences in these ratings, but lurasidone demonstrated significant within-group improvement from baseline on the MCCB composite score $(P=0.026)$ and on the Schizophrenia Cognition Rating Scale $(P<0.001)$, unlike ziprasidone. The very short duration of this trial, using a high dose of lurasidone $(120 \mathrm{mg} /$ day $)$ and the use of an incomplete battery of tests set some limits to this study, which now requires further work to evaluate the cognitive effects of lurasidone.

Secondary analysis of one trial evaluated the efficacy of lurasidone in patients with schizophrenia who were experiencing clinically significant depressive symptoms (Montgomery-Åsberg Depression Rating Scale [MADRS] > 12).$^{11}$ Lurasidone-treated patients had significantly improved mean MADRS scores in the total sample $(P=0.026)$ and in the subgroup with MADRS $>12$ $(P=0.04)$ compared with placebo (last observation carried forward). This trial is the only one to provide information on the efficacy of lurasidone in the treatment of depressive symptoms associated with schizophrenia. Double-blind Phase III trials are ongoing to confirm this potential benefit in schizophrenic patients with depressive symptoms.

The long-term efficacy of lurasidone in schizophrenia is being assessed from the extension phases of the short-term 


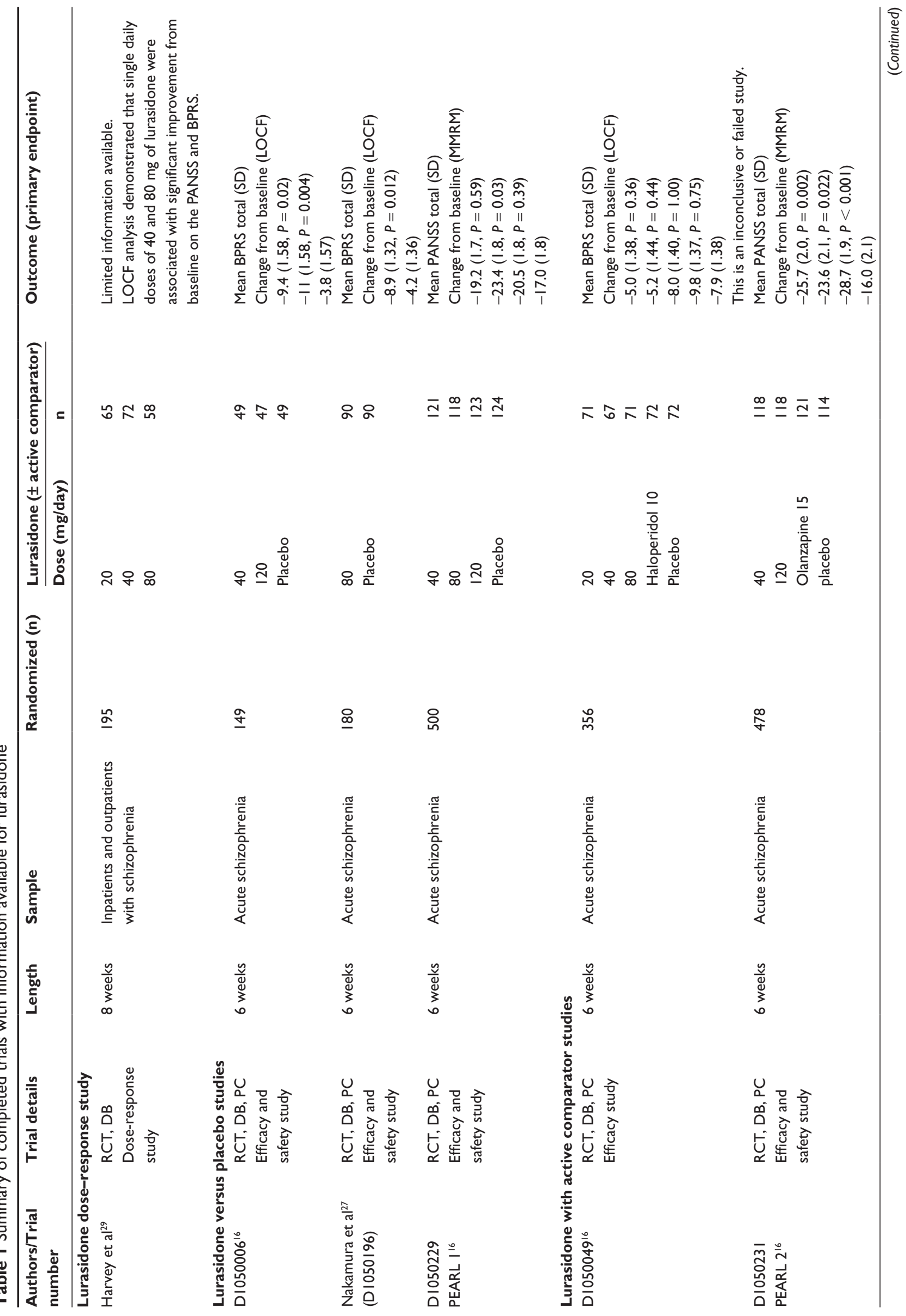




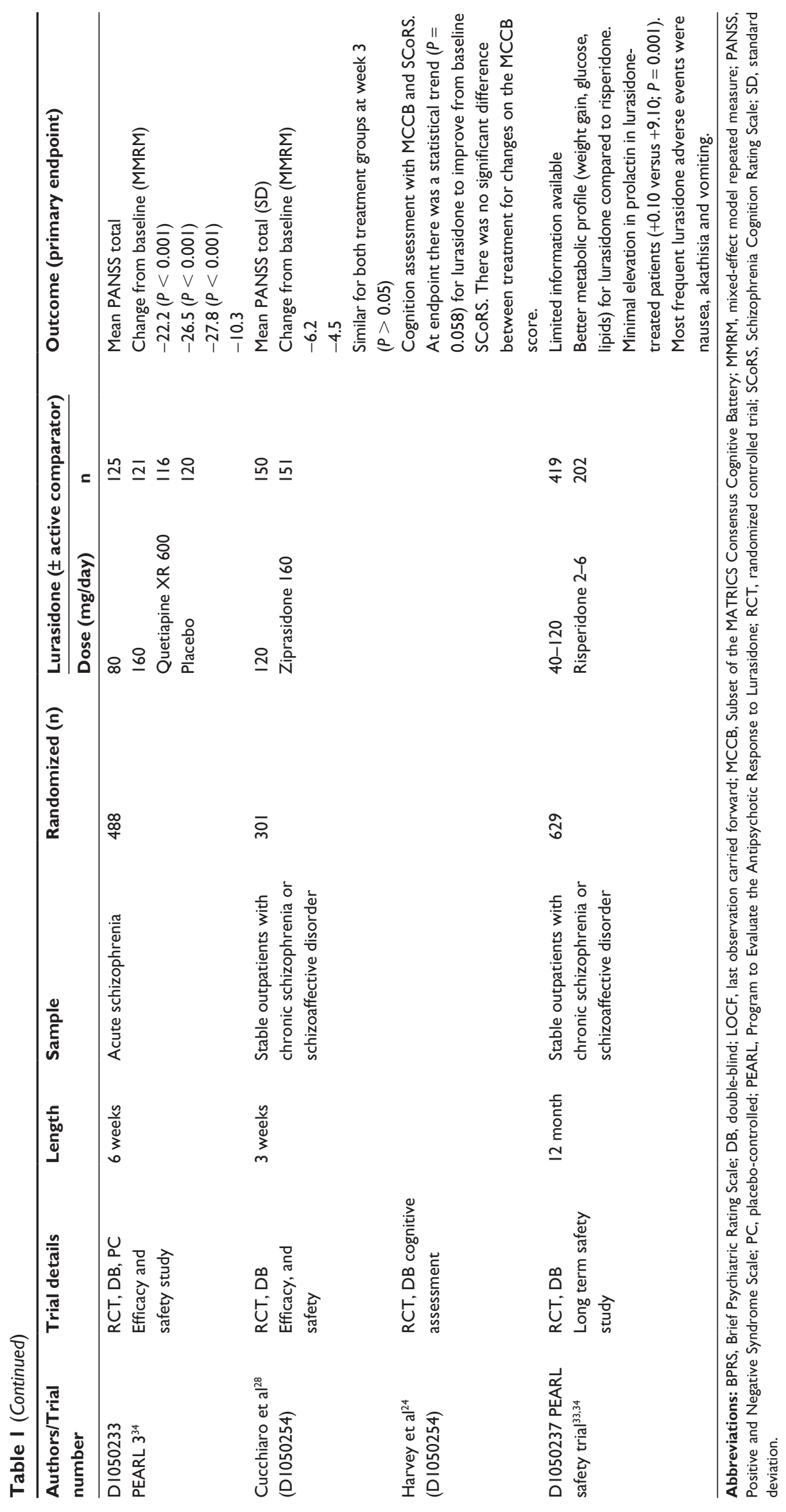


Table 2 Results of a pooled analysis based on a five-factor model of schizophrenia ${ }^{25}$

\begin{tabular}{|c|c|c|c|c|c|c|c|c|c|}
\hline \multirow{2}{*}{$\begin{array}{l}\text { Five PANSS } \\
\text { factor scores }\end{array}$} & \multicolumn{3}{|c|}{ Lurasidone 40 mg/day } & \multicolumn{3}{|c|}{ Lurasidone 80 mg/day } & \multicolumn{3}{|c|}{ Lurasidone 120 mg/day } \\
\hline & $\begin{array}{l}\text { Change from } \\
\text { baseline }\end{array}$ & $P$ & $\begin{array}{l}\text { Effect } \\
\text { size }\end{array}$ & $\begin{array}{l}\text { Change from } \\
\text { baseline }\end{array}$ & $P$ & $\begin{array}{l}\text { Effect } \\
\text { size }\end{array}$ & $\begin{array}{l}\text { Change from } \\
\text { baseline }\end{array}$ & $P$ & $\begin{array}{l}\text { Effect } \\
\text { size }\end{array}$ \\
\hline Positive factor & -7.92 & $<0.001$ & 0.35 & -8.48 & $<0.001$ & 0.47 & -8.25 & $<0.001$ & 0.42 \\
\hline Negative factor & -5.59 & $<0.001$ & $0.4 \mathrm{I}$ & -4.96 & 0.02 & 0.25 & -5.21 & 0.002 & 0.31 \\
\hline Disorganized thought & -4.86 & $<0.001$ & 0.40 & -5.10 & $<0.001$ & 0.47 & -5.22 & $<0.00$ I & 0.50 \\
\hline Hostility & -2.33 & $<0.013$ & 0.25 & -2.58 & 0.002 & 0.33 & -2.87 & $<0.001$ & 0.44 \\
\hline Depression/anxiety & -3.14 & 0.002 & 0.31 & -3.23 & 0.002 & 0.35 & -3.01 & 0.012 & 0.26 \\
\hline
\end{tabular}

Notes: Five PANSS factor scores were analysed using MMRM analysis. Adjusted effect sizes were calculated from an ANCOVA analysis (LOCF endpoint) as the betweentreatment group difference in least squares mean change scores divided by the pooled standard deviation of the change scores. Reprinted from Schizophrenia Research, II7, Loebel A, Cucchiaro J, Silva R, Ogasa M, Severs J, Marder SR, Efficacy of lurasidone in schizophrenia: Results of a pooled analysis based on a 5-factor model of schizophrenia, 267, 2010, with permission from Elsevier.

Abbreviations: ANCOVA, analysis of covariance; LOCF, last observation carried forward; MMRM, mixed-effect model repeated measure; PANSS, Positive and Negative Syndrome Scale.

trials and a six-month open-label extension trial evaluating the efficacy of lurasidone for the treatment of schizophrenia in subjects switched from other antipsychotic agents. Only data from Sunovion Pharmaceuticals have reported the maintenance of clinical effect in lurasidone-treated patients for up to eight months (6.5 months extension) in the PEARL (Program to Evaluate the Antipsychotic Response to Lurasidone) 2 extension trial. ${ }^{32}$

\section{Safety and tolerability}

The safety assessment is based on data from over 2600 human subjects exposed to lurasidone (in Phase I, II, and III studies) with almost 500 patients exposed for more than six months and 225 for more than one year. ${ }^{16}$ These data were assessed in the short-term trials already described and their long-term extension phases (Table 1). The first results of the PEARL safety trial over 12 months were also included. ${ }^{33,34}$ Additional information is provided in the product monograph. ${ }^{17}$ The dose range examined in the Phase II and III trials was 20-120 mg/day (doses up to $600 \mathrm{mg} /$ day were evaluated in Phase I trials).

\section{Common adverse events}

Safety data based on pooled analyses from five short-term, placebo-controlled studies included 1004 lurasidone-treated patients and 455 placebo-treated patients..$^{16,17,35}$ The most common adverse reactions (incidence $\geq 5 \%$ and at least twice the rate of placebo) in patients receiving lurasidone were akathisia $(15 \%)$, nausea $(12 \%)$, sedation $(12 \%)$, somnolence $(11 \%)$, parkinsonism (11\%), insomnia (8\%), agitation (6\%), anxiety (6\%), and dystonia (5\%). Apparent dose-related adverse reactions were akathisia and somnolence. Other common adverse events did not appear to be dose-related.

The long-term, risperidone-controlled trial substantiated the favorable profile of lurasidone, with a significantly lower incidence of somnolence, constipation, and weight increase (Table 3). ${ }^{33,34}$ This trial also suggested that akathisia, nausea, and vomiting may occur more frequently with lurasidone than with risperidone. Similar results were observed in a short-term, quetiapine-controlled trial. ${ }^{34}$ The short-term, ziprasidone-controlled trial found a statistically significant difference only in sedation. ${ }^{28}$

Table 3 Common adverse events for lurasidone versus active comparator ${ }^{28,33,34}$

\begin{tabular}{|c|c|c|c|c|c|c|c|c|}
\hline \multirow{3}{*}{$\begin{array}{l}\text { Adverse } \\
\text { event (\%) }\end{array}$} & \multicolumn{6}{|c|}{ Short-term trials } & \multirow{2}{*}{\multicolumn{2}{|c|}{$\begin{array}{l}\text { Long-term trials } \\
\text { D } 050237 \text { (1 } 2 \text { months) }\end{array}$}} \\
\hline & \multicolumn{2}{|c|}{ D 1050254 (3 weeks) } & \multicolumn{4}{|c|}{ DI050233 PEARL 3 (6 weeks) } & & \\
\hline & $\begin{array}{l}\text { Lurasidone } \\
\text { I } 20 \mathrm{mg} / \text { day }\end{array}$ & $\begin{array}{l}\text { Ziprasidone } \\
160 \text { mg/day }\end{array}$ & $\begin{array}{l}\text { Lurasidone } \\
80 \mathrm{mg} / \text { day }\end{array}$ & $\begin{array}{l}\text { Lurasidone } \\
160 \mathrm{mg} / \mathrm{day}\end{array}$ & $\begin{array}{l}\text { Quetiapine } \\
600 \mathrm{mg} / \mathrm{day}\end{array}$ & Placebo & $\begin{array}{l}\text { Lurasidone } \\
40-120 \mathrm{mg} / \text { day }\end{array}$ & $\begin{array}{l}\text { Risperidone } \\
\text { 2-6 mg/day }\end{array}$ \\
\hline Akathisia & 3.3 & 6.6 & 8 & 9 & 2 & 1 & 14.3 & 7.9 \\
\hline Nausea & 7.3 & 4.6 & 8 & 6.6 & 3.4 & 3.3 & 16.7 & 10.9 \\
\hline Vomiting & 8 & 4 & - & - & - & - & 10 & 3.3 \\
\hline Parkinsonism & - & - & 5.6 & 6.6 & 3.4 & 0 & 4.3 & 5.4 \\
\hline Somnolence & 6.7 & 9.9 & 4 & 6.6 & 13.4 & 0.8 & 13.6 & 17.8 \\
\hline Sedation & 4.7 & 11.3 & - & - & - & - & - & - \\
\hline Insomnia & 10.7 & 9.3 & - & - & - & - & - & - \\
\hline Headache & 6.7 & 4.6 & - & - & - & - & - & - \\
\hline Dizziness & 2.7 & 6.6 & 4.8 & 5.8 & 13.4 & 1.7 & - & - \\
\hline Dry mouth & - & - & 1.6 & 1.7 & 7.6 & 0.8 & - & - \\
\hline Constipation & - & - & 2.4 & 0.8 & 6.7 & 2.5 & 1.9 & 6.9 \\
\hline Weight gain & - & - & 0.8 & 1.7 & 6.7 & 0.8 & 9.3 & 19.8 \\
\hline
\end{tabular}




\section{Extrapyramidal symptoms, akathisia, and dyskinesias}

Data provided by clinical trials were assessed on the Simpson Angus Rating Scale for extrapyramidal symptoms, the Barnes Akathisia Scale for akathisia, and the Abnormal Involuntary Movement Scale for dyskinesias. In the short-term, fixed-dose, placebo-controlled trials for schizophrenia, treatment-emergent extrapyramidal side effects (excluding akathisia and restlessness) were observed in $14.7 \%$ of lurasidone-treated patients compared with 5.1\% of placebo-treated patients. ${ }^{16,17}$ Akathisia was observed in $15 \%$ of lurasidone-treated patients compared with $3.3 \%$ of placebo-treated patients. The incidence of dystonia for lurasidone-treated patients was $4.7 \%$ versus $0.7 \%$ for placebo-treated patients.

The mean change from baseline for lurasidone-treated patients was comparable with placebo-treated patients for extrapyramidal symptoms and dyskinesias, and was very close to placebo-treated patients for akathisia (lurasidone 0.2 , placebo 0.0 ). The percentage of patients who shifted from normal to abnormal was greater in lurasidone-treated patients versus placebo for the Barnes Akathisia Scale (lurasidone 16\%, placebo 7.6\%) and the Simpson Angus Rating Scale (lurasidone $5.3 \%$, placebo $2.5 \%$ ). Only akathisia appeared to be dose-related, but the greatest incidence of extrapyramidal side effect (including dystonia) occurred with the highest dose of lurasidone $(120 \mathrm{mg} /$ day $)$. Akathisia is a common neurological adverse event with lurasidone, and is the most often reported side effect. Reported extrapyramidal side effects amounted to $22 \%$ and reported dystonia to $7 \%$ for patients treated with lurasidone doses of $120 \mathrm{mg}$ daily. Longterm treatment with antipsychotic drugs, especially at high dosages, is associated with the risk of tardive dyskinesia. Data on the potential risk for tardive dyskinesia are still lacking, because of the limited information available from long-term clinical trials.

\section{Metabolic side effects}

\section{Glucose metabolism}

Pooled data from short-term, placebo-controlled studies showed a mean increase in fasting glucose of $1.4 \mathrm{mg} / \mathrm{dL}$ in the lurasidone group compared with a $0.6 \mathrm{mg} / \mathrm{dL}$ increase in the placebo group. ${ }^{16,17,35}$ There was no dose-response relationship in the lurasidone group (Table 4). Changes in fasting glucose (mean from baseline and proportion of patients with shifts to $\geq 126 \mathrm{mg} / \mathrm{dL}$ ) in lurasidone-treated patients were not statistically different from placebo-treated patients.

The uncontrolled longer-term trials (primarily open-label extension studies) reported a mean change in glucose of $+1.6 \mathrm{mg} / \mathrm{dL}$ at week $24(\mathrm{n}=186),+0.3 \mathrm{mg} / \mathrm{dL}$ at week 36 $(\mathrm{n}=236)$, and $+1.2 \mathrm{mg} / \mathrm{dL}$ at week $52(\mathrm{n}=244) \cdot{ }^{17}$

In trials with an active comparator, a similar change in glucose was reported between lurasidone and ziprasidone $(+4.7$ versus $+4.8 \mathrm{mg} / \mathrm{dL}){ }^{28}$ In pooled short-term trial analysis, the median changes in glucose associated with lurasidone was unchanged (0.0), increased for olanzapine and haloperidol ( +4.0 and +2.0 , respectively), and for placebo remained essentially unchanged (+1.0). ${ }^{16}$ In a longer-term safety trial, the median change from baseline in glucose observed was significantly different $(P=0.001)$ in favor of lurasidone, with a mean decrease of $-0.5 \mathrm{mg} / \mathrm{dL}$ versus a mean increase of $3.0 \mathrm{mg} / \mathrm{dL}$ for risperidone. ${ }^{33,34}$

\section{Dyslipidemia}

In short-term trials, mean increases were not observed for total cholesterol, low-density lipoprotein cholesterol, or triglyceride indices in the lurasidone group (Table 4)..$^{16,17,35}$ Changes in fasting cholesterol and triglycerides (mean

Table 4 Metabolic effects of lurasidone from short-term trials ${ }^{16,17}$

\begin{tabular}{|c|c|c|c|c|c|}
\hline & \multirow[t]{2}{*}{ Placebo } & \multicolumn{4}{|l|}{ Lurasidone } \\
\hline & & $20 \mathrm{mg} /$ day & $40 \mathrm{mg} /$ day & $80 \mathrm{mg} /$ day & $120 \mathrm{mg} /$ day \\
\hline \multicolumn{6}{|l|}{ Glucose } \\
\hline Mean change from baseline $(\mathrm{mg} / \mathrm{dL})$ & -0.7 & -0.6 & 2.5 & -0.9 & 2.5 \\
\hline$\geq 126 \mathrm{mg} / \mathrm{dL}(\%)$ & 8.6 & 11.7 & 14.3 & 10.0 & 10.0 \\
\hline \multicolumn{6}{|l|}{ Total cholesterol } \\
\hline Mean change from baseline $(\mathrm{mg} / \mathrm{dL})$ & -8.5 & -12.3 & -9.4 & -9.8 & -3.8 \\
\hline$\geq 240 \mathrm{mg} / \mathrm{dL}(\%)$ & 6.6 & 13.8 & 7.3 & 6.9 & 3.8 \\
\hline \multicolumn{6}{|l|}{ Triglycerides } \\
\hline Mean change from baseline $(\mathrm{mg} / \mathrm{dL})$ & -15.7 & -29.1 & -6.2 & -14.2 & -3.1 \\
\hline$\geq 200 \mathrm{~m} \mathrm{~g} / \mathrm{dL}(\%)$ & 12.5 & 14.3 & 14.0 & 8.7 & 10.5 \\
\hline \multicolumn{6}{|l|}{ Weight } \\
\hline Mean change from baseline $(\mathrm{kg})$ & 0.26 & -0.15 & 0.67 & 1.14 & 0.68 \\
\hline
\end{tabular}


from baseline and proportion of patients with shifts) in lurasidone-treated patients were not significantly different from placebo-treated patients.

The uncontrolled longer-term studies (primarily openlabel extension studies) reported no increase in mean change of total cholesterol and triglycerides. ${ }^{17}$ Lurasidone was associated with a mean change in total cholesterol and triglycerides $(\mathrm{mg} / \mathrm{dL})$ of $-4.2(\mathrm{n}=186)$ and $-13.6(\mathrm{n}=187)$ at week $24,-1.9(\mathrm{n}=238)$ and $-3.5(\mathrm{n}=238)$ at week 36 , and -3.6 $(\mathrm{n}=243)$ and $-6.5(\mathrm{n}=243)$ at week 52 , respectively.

In active comparator-controlled studies, treatment with lurasidone versus ziprasidone was associated with a greater reduction in triglycerides $(-2.6$ versus $+22.4 \mathrm{mg} / \mathrm{dL})$ and similar endpoint reduction in total cholesterol $(-6.4$ versus $-4.4 \mathrm{mg} / \mathrm{dL}) .{ }^{28} \mathrm{In}$ pooled analysis of the short-term studies, the median endpoint change in the lurasidone, haloperidol, and placebo groups decreased for total cholesterol and triglycerides, $(-8.0,-8.0,-10 \mathrm{mg} / \mathrm{dL}$ and $-5.0,-3.0$ and $-7.0 \mathrm{mg} / \mathrm{dL}$, respectively) and in the olanzapine group increased significantly more $(+9.0$ and $+25.0 \mathrm{mg} / \mathrm{dL}) .{ }^{16}$ In the PEARL 3 trial, triglyceride levels on lurasidone decreased in a similar fashion to that on placebo (placebo -9.0, lurasidone $80 \mathrm{mg}$ /day -2.0 and lurasidone $160 \mathrm{mg} /$ day $-9.0 \mathrm{mg} / \mathrm{dL}$ ), compared with quetiapine, which increased triglyceride levels $(+8.0 \mathrm{mg} / \mathrm{dL}) \cdot{ }^{32,34} \mathrm{In}$ a long-term safety trial, the median change from baseline for lipid variables decreased similarly in lurasidone and risperidone groups..$^{33,34}$

\section{Weight gain}

Pooled data analysis from the short-term trials showed a mean increase in weight of $0.75 \mathrm{~kg}$ in the lurasidone group and of $0.26 \mathrm{~kg}$ in the placebo group. ${ }^{16,17}$ The proportion of patients with a weight increase $\geq 7 \%$ was $5.6 \%$ for lurasidone-treated patients and $4 \%$ for placebo-treated patients. The weight gain did not appear to be related to lurasidone dose. The greatest weight gain was $1.14 \mathrm{~kg}$ and occurred with the middle dose of lurasidone (80 mg/day, Table 4).

The uncontrolled longer-term studies reported no increase in weight. Lurasidone was associated with a mean change in weight of $-0.38 \mathrm{~kg}(\mathrm{n}=531)$ at week $24,-0.47 \mathrm{~kg}(\mathrm{n}=303)$ at week 36 , and $-0.71 \mathrm{~kg}(\mathrm{n}=244)$ at week $52 .{ }^{17}$

In trials with active comparators, the median endpoint change in weight at week 3 was similar for lurasidone and ziprasidone $\left(-0.65 \mathrm{~kg}\right.$ versus $-0.35 \mathrm{~kg}$, respectively).$^{28} \mathrm{In}$ pooled short-term trial analysis, weight gain $\geq 7 \%$ in the lurasidone, haloperidol, and placebo groups was similar (5.6\%, 4.2\%, and 4\%, respectively) and much more frequent in the olanzapine group (34.4\%). ${ }^{16}$ In the PEARL 3 trial, weight gain with lurasidone and placebo was similar (placebo $+0.1 \mathrm{~kg}$, lurasidone $+0.6 \mathrm{~kg}$ ) compared with quetiapine, which caused more weight gain $(+2.1 \mathrm{~kg}) .{ }^{32,34}$

A long-term safety trial reported a mean change in weight at month 12 of $-0.9 \mathrm{~kg}$ in the lurasidone group and $+2.6 \mathrm{~kg}$ in the risperidone group. Unlike risperidone, which increased weight continuously over the 12 months, lurasidone did not change patient weight from the third month. ${ }^{33,34}$

\section{Hyperprolactinemia}

In short-term trials, the only significant difference found in the lurasidone group compared with the placebo group was the mean change from baseline in prolactin. ${ }^{16,17}$ Pooled data analysis from these trials showed a mean change from baseline in prolactin levels of $1.1 \mathrm{ng} / \mathrm{mL}$ for lurasidone-treated patients and $-0.6 \mathrm{ng} / \mathrm{mL}$ for placebo-treated patients. The increase in prolactin concentrations was dose-dependent and slightly greater in female patients. The greatest prolactin level occurred for the highest dose of lurasidone (120 mg/ day) and in women $(6.7 \mathrm{ng} / \mathrm{mL})$.

Conversely, the uncontrolled longer-term trials (primarily open-label extensions) reported no increase in prolactin concentrations. ${ }^{17}$ Lurasidone was associated with a median change in prolactin of $-1.9 \mathrm{ng} / \mathrm{mL}(\mathrm{n}=188)$ at week 24 , $-5.4 \mathrm{ng} / \mathrm{mL}(\mathrm{n}=189)$ at week 36 , and $-3.3 \mathrm{ng} / \mathrm{mL}(\mathrm{n}=243)$ at week 52 .

In pooled short-term studies with active comparator controls, the median endpoint change was highest in the haloperidol group $(+8.5 \mathrm{ng} / \mathrm{mL})$, then in the olanzapine and lurasidone group $(+3.4 \mathrm{ng} / \mathrm{dL}$ and $+1.1 \mathrm{ng} / \mathrm{dL})$ compared with the placebo group $(+0.5 \mathrm{ng} / \mathrm{mL}) .{ }^{16}$

In a long-term safety trial, the median changes from baseline in prolactin levels significantly favored lurasidonetreated patients compared with the risperidone group $(+0.10$ $[\mathrm{n}=378]$ versus $+9.10[\mathrm{n}=176] \mathrm{ng} / \mathrm{mL}$ at month 12 , $P=0.001)$. $^{33,34}$

\section{Cardiovascular side effects}

In the short-term lurasidone trials, there have been no reports of increased QTc > $500 \mathrm{msec}$ and no cases observed with electrocardiographic abnormalites. ${ }^{16,17}$ Mean QTc change was $+1.5 \mathrm{msec}(\mathrm{n}=972)$ for lurasidone, $-2.8 \mathrm{msec}(\mathrm{n}=67)$ for haloperidol, $+4.1 \mathrm{msec}(\mathrm{n}=121)$ for olanzapine, and $+1.9 \operatorname{msec}(n=436)$ for placebo. Comparison of lurasidone and ziprasidone over a three-week period found no clinically significant elevations in QTc, although lurasidone treatment was associated with a lower endpoint change in QTc $(+0.3 \mathrm{msec}$ versus $+3.3 \mathrm{msec}) .{ }^{28}$ 
The low affinity for $\alpha_{1}$-adrenergic receptors should ensure a low risk of orthostatic hypotension. The percentage of patients with orthostatic hypotension from short-term trials was low (lurasidone $40 \mathrm{mg} /$ day, $0.8 \%$; lurasidone $80 \mathrm{mg}$ / day, $1.4 \%$; lurasidone $120 \mathrm{mg} /$ day, and $1.7 \%$, and $0.9 \%$ with placebo). ${ }^{17}$

\section{Summary of safety data}

In summary, lurasidone is well tolerated, especially with regard to metabolic effects. Although results of the preclinical studies suggested that lurasidone had a low potential for causing clinically significant extrapyramidal symptoms, these were observed with a higher frequency than expected.

There were no signs of glucose elevation or lipid changes with lurasidone. There was a small increase in weight with lurasidone, presumably related to the low affinity for $5 \mathrm{HT}_{2 \mathrm{C}}$ receptors and no affinity for histaminic $\mathrm{H}_{1}$ receptors. Like ziprasidone, but unlike olanzapine, risperidone, and quetiapine, lurasidone has a neutral effect on weight and on glucose or lipid metabolism.

Lurasidone increases prolactin levels at the beginning of treatment. This increase appears to be dose-related and different in men and women. In no trials were there any clinically relevant changes in vital signs and electrocardiographic recordings. However, most current data from short-term studies and several longer trials are in progress, with data not yet available. The results of these studies are awaited in order to assess the long-term safety profile of lurasidone.

\section{Place of lurasidone in clinical practice}

Lurasidone has been shown to be efficacious in the treatment of the acute phase of schizophrenia, and seems to be well tolerated. It is a further member of the array of chemical entities classified as second-generation antipsychotics recently adopted by the FDA for this indication.

Accordingly, it was of interest to determine the position of lurasidone with respect to the other second-generation antipsychotics in practical clinical use. Because of the heterogeneity of this drug class, the choice of a second-generation antipsychotic in practice is made according to its tolerability profile. Tolerability profiles of the different second-generation antipsychotics available are compared and presented in Table 5. ${ }^{36}$ While the side effects of first-generation antipsychotics are dominated by extrapyramidal symptoms, second-generation antipsychotics are often associated with a risk of secondary metabolic effects (weight gain, diabetes, or dyslipidemia). Lurasidone, like other recent second-generation antipsychotics (aripiprazole, asenapine, and ziprasidone), is distinguished by its good metabolic tolerability profile. Lurasidone does not appear to have any significant adverse impact on metabolic indices, unlike other second-generation antipsychotics such as olanzapine and clozapine, and, to a lesser extent, risperidone and quetiapine. Lurasidone is also associated with good cardiovascular tolerability, without hypertension or widening of QT interval, whatever the dosage used.

However, it has a significant impact, albeit moderate, on the occurrence of akathisia, extrapyramidal symptoms,

Table 5 Adverse effects of lurasidone compared with those of other antipsychotics

\begin{tabular}{|c|c|c|c|c|c|c|c|}
\hline Drug & QT prolongation & Hypotension & Sedation & Weight gain & $\begin{array}{l}\text { Metabolic } \\
\text { syndrome }\end{array}$ & $\begin{array}{l}\text { Extrapyramidal } \\
\text { symptoms }\end{array}$ & $\begin{array}{l}\text { Prolactin } \\
\text { elevation }\end{array}$ \\
\hline Lurasidone & - & - & + & $+/-$ & - & + & $+/-*$ \\
\hline Amisulpride & + & - & - & + & + & + & +++ \\
\hline Aripiprazole & - & - & - & $+/-$ & $+l-$ & $+/-$ & - \\
\hline Asenapine & + & - & - & $+/-$ & - & $+1-$ & $+/-$ \\
\hline Chlorpromazine & ++ & +++ & +++ & ++ & ++ & ++ & +++ \\
\hline Clozapine & + & +++ & +++ & +++ & +++ & - & - \\
\hline Haloperidol & ++ & + & + & + & + & +++ & +++ \\
\hline Olanzapine & + & + & ++ & +++ & +++ & $+/-$ & + \\
\hline Paliperidone & + & ++ & + & ++ & ++ & + & +++ \\
\hline Quetiapine & ++ & ++ & ++ & ++ & ++ & - & - \\
\hline Risperidone & + & ++ & + & ++ & ++ & + & +++ \\
\hline Sertindole & +++ & +++ & - & + & + & - & $+/-$ \\
\hline Sulpiride & + & - & - & + & + & + & +++ \\
\hline Ziprasidone & +++ & + & + & $+/-$ & $+/-$ & $+/-$ & $+/-$ \\
\hline
\end{tabular}

Notes: *Short-term trials reported an increase and long-term safety study found no increase in prolactin levels. Adapted from The Maudsley Prescribing Guidelines I0th ed; 36 reproduced with permission from the publisher.

Abbreviations: +++, high incidence/severity; ++, moderate incidence/severity; +, low incidence/severity; -, very low incidence/severity. 
and hyperprolactinemia at the start of treatment. These side effects bring it closer to the first-generation antipsychotics, or risperidone and paliperidone, than to other second-generation antipsychotics. The use of lurasidone thus appears to be of particular interest in patients presenting with or vulnerable to endocrine (diabetes, dyslipidemia) or cardiovascular comorbidities, or who are overweight.

Continuous prophylactic antipsychotic treatment reduces the risk of relapse by approximately $70 \% .{ }^{37} \mathrm{~A}$ trial has demonstrated that even short medication gaps, including periods from 1-10 days, are associated with an increase in the risk of hospitalization. ${ }^{38}$ Noncompliance with antipsychotic medication is often considered to be the most important factor related to relapse. Treatment-related issues that may affect compliance are primarily related to the efficacy and tolerability of antipsychotics. In a post hoc analysis of a study conducted in Germany on a sample of schizophrenic patients, their compliance with antipsychotic medication was strongly associated with subjective well-being, and further factors were clinical symptoms and side effects. ${ }^{39}$

The overall tolerability profile of lurasidone compared with other second-generation antipsychotics appears to be compatible with good patient acceptability and good compliance. As with other recently commercialized secondgeneration antipsychotics, it would be of interest to evaluate the efficacy of lurisadone in real-world conditions, by measuring the time elapsed before cessation of treatment for whatever cause, as in the CUtLASS and CATIE trials. These studies demonstrated that patients treated with neuroleptics and second-generation antipsychotics had similar levels of compliance, with a high dropout rate, and that these findings might be due in part to the fact that second-generation agents induced another range of side effects, including weight gain, impaired glucose tolerance, and dyslipidemia. ${ }^{12,13}$ Once again, the favorable metabolic profile of lurasidone may be associated with a longer treatment time than with the other antipsychotics. However, it also seems necessary to evaluate akathisia in subjective well-being and its effect on patient compliance.

In addition to its affinity for $\mathrm{D}_{2}$ and $5-\mathrm{HT}_{2 \mathrm{~A}}$ receptors, lurasidone has high affinity for $5 \mathrm{HT}_{7}, 5 \mathrm{HT}_{1 \mathrm{~A}}$, and $\alpha_{2 \mathrm{C}}$ receptors that may be involved in the improvement of cognitive and thymic symptoms in schizophrenic patients. Only one trial evaluating the cognitive effect of lurasidone is available to date. ${ }^{24}$ As we have seen, it presents several methodological limitations and does not yield significant results. Likewise, we have limited information on the efficacy of lurasidone for depressive symptoms in schizophrenic patients. ${ }^{31}$ If firm evidence were found for improved cognitive dysfunction or depressive symptoms in patients, then lurasidone would stand out among the other second-generation antipsychotics for efficacy.

In summary, lurasidone offers several advantages over other second-generation antipsychotics, ie, simple practical use (daily dose, administration possible with food), early efficacy, and good tolerability, in particular cardiometabolic. This new tolerability profile further extends the heterogeneity of the class of second-generation antipsychotics, and supports the view of some authors that this classification needs to be reviewed. ${ }^{40}$ Other therapeutic perspectives for lurasidone are being evaluated, in particular for bipolar depression with the ongoing PREVAIL 1, 2, 3 (PRogram to Evaluate Antidepressant Impact of Lurasidone) and maintenance trials, designed to assess the efficacy of lurasidone as monotherapy, addon therapy, and prophylaxis for this indication.

\section{Disclosure}

The authors report no conflicts of interest in this work.

\section{References}

1. Tandon R, Keshavan MS, Nasrallah HA. Schizophrenia, "just the facts" what we know in 2008. 2. Epidemiology and etiology. Schizophr Res. 2008;102(1-3):1-18.

2. Kane J, Honigfeld G, Singer J, Meltzer H. Clozapine for the treatmentresistant schizophrenic. A double-blind comparison with chlorpromazine. Arch Gen Psychiatry. 1988;45(9):789-796.

3. Lieberman JA, Mailman RB, Duncan G, et al. Serotonergic basis of antipsychotic drug effects in schizophrenia. Biol Psychiatry. 1998;44(11):1099-1117.

4. Buchanan RW, Kreyenbuhl J, Kelly DL, et al. The 2009 schizophrenia PORT psychopharmacological treatment recommendations and summary statements. Schizophr Bull. 2009;36(1):71-93.

5. Falkai P, Wobrock T, Lieberman J, Glenthoj B, Gattaz WF, Moller HJ. World Federation of Societies of Biological Psychiatry (WFSBP) guidelines for biological treatment of schizophrenia, Part 1. Acute treatment of schizophrenia. World J Biol Psychiatry. 2005;6(3): 132-191.

6. Lehman AF, Lieberman JA, Dixon LB, et al. Practice guideline for the treatment of patients with schizophrenia, second edition. Am J Psychiatry. 2004;161(2 Suppl):1-56.

7. Moore TA, Buchanan RW, Buckley PF, et al. The Texas Medication Algorithm Project antipsychotic algorithm for schizophrenia: 2006 update. J Clin Psychiatry. 2007;68(11):1751-1762.

8. Bagnall AM, Jones L, Ginnelly L, et al. A systematic review of atypical antipsychotic drugs in schizophrenia. Health Technol Assess. 2003;7(13):1-193.

9. Geddes J, Freemantle N, Harrison P, Bebbington P. Atypical antipsychotics in the treatment of schizophrenia: Systematic overview and meta-regression analysis. BMJ. 2000;321(7273):1371-1376.

10. Leucht S, Corves C, Arbter D, Engel RR, Li C, Davis JM. Secondgeneration versus first-generation antipsychotic drugs for schizophrenia: A meta-analysis. Lancet. 2009;373(9657):31-41.

11. Leucht S, Komossa K, Rummel-Kluge C, et al. A meta-analysis of head-to-head comparisons of second-generation antipsychotics in the treatment of schizophrenia. Am J Psychiatry. 2009;166(2): $152-163$. 
12. Jones PB, Barnes TR, Davies L, et al. Randomized controlled trial of the effect on quality of life of second- vs first-generation antipsychotic drugs in schizophrenia: Cost Utility of the Latest Antipsychotic Drugs in Schizophrenia Study (CUtLASS 1). Arch Gen Psychiatry. 2006;63(10): 1079-1087.

13. Lieberman JA, Stroup TS, McEvoy JP, et al. Effectiveness of antipsychotic drugs in patients with chronic schizophrenia. $N$ Engl J Med. 2005;353(12):1209-1223.

14. Rummel-Kluge C, Komossa K, Schwarz S, et al. Second-generation antipsychotic drugs and extrapyramidal side effects: A systematic review and meta-analysis of head-to-head comparisons. Schizophr Bull. May 31, 2010. [Epub ahead of print].

15. Rummel-Kluge C, Komossa K, Schwarz S, et al. Head-to-head comparisons of metabolic side effects of second generation antipsychotics in the treatment of schizophrenia: A systematic review and meta-analysis. Schizophr Res. 2010;123(2-3):225-233.

16. Food and Drug Administration. Drug approval package Latuda (lurasidone hydrochloride) tablets: Available from: http://www.accessdata.fda. gov/drugsatfda_docs/nda/2010/200603Orig1s000TOC.cfm; Accessed May 9, 2010.

17. Latuda (lurasidone $\mathrm{HCl}$ ) tablets prescribing information. Available from: http://www.latuda.com/LatudaPrescribingInformation.pdf; Accessed May 9, 2010.

18. Meyer JM, Loebel AD, Schweizer E. Lurasidone: A new drug in development for schizophrenia. Expert Opin Investig Drugs. 2009;18(11): 1715-1726.

19. Ishibashi T, Horisawa T, Tokuda K, et al. Pharmacological profile of lurasidone, a novel antipsychotic agent with potent 5-hydroxytryptamine 7 (5-HT7) and 5-HT1A receptor activity. J Pharmacol Exp Ther. 2010;334(1):171-181.

20. Guscott M, Bristow LJ, Hadingham K, et al. Genetic knockout and pharmacological blockade studies of the 5-HT7 receptor suggest therapeutic potential in depression. Neuropharmacology. 2005;48(4):492-502.

21. Meneses A. Effects of the 5-HT7 receptor antagonists SB-269970 and DR 4004 in autoshaping Pavlovian/instrumental learning task. Behav Brain Res. 2004;155(2):275-282.

22. Terry AV Jr, Buccafusco JJ, Wilson C. Cognitive dysfunction in neuropsychiatric disorders: Selected serotonin receptor subtypes as therapeutic targets. Behav Brain Res. 2008;195(1):30-38.

23. Citrome L. Lurasidone for schizophrenia: A brief review of a new second-generation antipsychotic. Clin Schizophr Relat Psychoses. 2011;4(4):251-257.

24. Harvey PD, Ogasa M, Cucchiaro J, Loebel A, Keefe RS. Performance and interview-based assessments of cognitive change in a randomized, double-blind comparison of lurasidone vs ziprasidone. Schizophr Res. 2011;127(1-3):188-194.

25. Loebel A, Cucchiaro J, Silva R, Ogasa M, Severs J, Marder SR. Efficacy of lurasidone in schizophrenia: Results of a pooled analysis based on a 5-factor model of schizophrenia. Schizophr Res. 2010;117:267.
26. Citrome L. Lurasidone for schizophrenia: A review of the efficacy and safety profile for this newly approved second-generation antipsychotic. Int J Clin Pract. 2011;65(2):189-210.

27. Nakamura M, Ogasa M, Guarino J, et al. Lurasidone in the treatment of acute schizophrenia: A double-blind, placebo-controlled trial. J Clin Psychiatry. 2009;70(6):829-836.

28. Cucchiaro J, Potkin S, Ogasa M, Loebel A. A double-blind comparaison of the safety and efficacy of lurasidone and ziprasidone in clinically stable outpatients with schizophrenia or schizoaffective disorder. Schizophr Bull. 2009;35 Suppl 1:342-343.

29. Harvey PD, Murasaki M, Cucchiaro J, Ogasa M, Loebel A. A three arm dose finding study of lurasidone: Efficacy and tolerability data. Schizophr Res. 2010;117:374-375.

30. Good KP, Rabinowitz J, Whitehorn D, Harvey PD, DeSmedt G, Kopala LC. The relationship of neuropsychological test performance with the PANSS in antipsychotic naive, first-episode psychosis patients. Schizophr Res. 2004;68(1):11-19.

31. Ogasa M, Loebel A, Cucchiaro J, et al. Effect of lurasidone on depressive symptoms in patients with schizophrenia. Schizophr Bull. 2009;35: 344-345.

32. Dainippon. Second quarter financial results for FY2010. Presentation slides. Available from: http://www.ds-pharma.com/pdf_view. php?id=55; Accessed May 9, 2010.

33. Dainippon. Completion of long-term phase 3 safety trial for Latuda ${ }^{\circledR}$ (lurasidone $\mathrm{HCl}$ ): Available from: http://www.ds-pharma.com/news/ pdf/ene20110125_.pdf; Accessed May 9, 2011.

34. Dainippon. Latuda meeting January 2011. Presentation slides: Available from: http://www.ds-pharma.com/ir/presentation/img/eir20110125_1. pdf; Accessed May 9, 2011.

35. Cucchiaro J, Pikalov A, Ogasa M. Safety of lurasidone: Pooled analysis of five placebo-controlled trials in patients with schizophrenia. Int $J$ Neuropsychopharmacol. 2010;13 Suppl 1:217.

36. Taylor D, Paton C, Kapur S. The Maudsley Prescribing Guidelines 10th Edition. London, UK: Informa Healthcare; 2009.

37. Lindenmayer JP, Liu-Seifert H, Kulkarni PM, et al. Medication nonadherence and treatment outcome in patients with schizophrenia or schizoaffective disorder with suboptimal prior response. J Clin Psychiatry. 2009;70(7):990-996.

38. Weiden PJ, Kozma C, Grogg A, Locklear J. Partial compliance and risk of rehospitalization among California Medicaid patients with schizophrenia. Psychiatr Serv. 2004;55(8):886-891.

39. Karow A, Czekalla J, Dittmann RW, et al. Association of subjective well-being, symptoms, and side effects with compliance after 12 months of treatment in schizophrenia. J Clin Psychiatry. 2007;68(1):75-80.

40. Leucht S, Kissling W, Davis JM. Second-generation antipsychotics for schizophrenia: Can we resolve the conflict? Psychol Med. 2009;39(10): 1591-1602.
Therapeutics and Clinical Risk Management

\section{Publish your work in this journal}

Therapeutics and Clinical Risk Management is an international, peerreviewed journal of clinical therapeutics and risk management, focusing on concise rapid reporting of clinical studies in all therapeutic areas, outcomes, safety, and programs for the effective, safe, and sustained use of medicines. This journal is indexed on PubMed Central, CAS,
Dovepress

EMBase, Scopus and the Elsevier Bibliographic databases. The manuscript management system is completely online and includes a very quick and fair peer-review system, which is all easy to use. Visit http://www.dovepress.com/testimonials.php to read real quotes from published authors. 